\title{
PERANCANGAN BUSANA WANITA SIAP PAKAI DENGAN INSPIRASI BUDAYA SUKU KALASH DI PAKISTAN
}

\author{
Abel Della Sisilia ${ }^{1)}$, Dewi Isma Aryani ${ }^{2)}$, Tan, Indra Janty ${ }^{3)}$ \\ Program Diploma-III Seni Rupa dan Desain, \\ Fakultas Seni Rupa dan Desain, Universitas Kristen Maranatha \\ Jl. Prof.drg.Surya Sumantri, MPH no. 65 Bandung, Indonesia
}

Email: abeldella14@gmail.com

\begin{abstract}
Abstrak
Suku Kalash merupakan suku minoritas yang terletak di Chitral, Pakistan dan keberadaannya pun terancam punah. Suku Kalash menerapkan modernisasi pada pakaian tradisionalnya yaitu Piran dengan menambahkan ornamen bordir dan manik-manik yang didapat dari luar lingkungan Suku Kalash. Keberadaan ornamen bordir dan manik pada, busana tradisional Suku Kalash menjadi salah satu unsur penarik perhatian masyarakat di luar Suku Kalash sehingga mampu menarik wisatawan untuk berkunjung ke perkampungan mereka. Metode penelitian yang digunakan adalah eksperimen kualitatif berdasarkan studi literatur dan observasi beberapa referensi busana tradisional suku-suku masyarakat dunia. Pakaian dan motif dalam budaya Suku Kalash menjadi inspirasi perancangan koleksi busana siap pakai wanita dengan menerapkan siluet A-Line dan H-Line. Reka tekstil yang diterapkan pada busana adalah unsur gathering dengan stilasi motif asli melalui teknik bordir dan manik-manik. Hasil dari perancangan koleksi busana siap pakai wanita ini ditujukan untuk wanita dewasa kalangan menengah ke atas dengan rentang usia 23-33 tahun, berkarakter mudah bergaul, ceria, dan feminin, berkepribadian menarik, menyukai seni dan warna-warna terang serta berani.
\end{abstract}

Kata Kunci: Bordir, Busana Tradisional, Manik-manik, Modernisasi, Suku Kalash

\begin{abstract}
The Kalash tribe is a minority tribe located in Chitral, Pakistan and its existence is threatened with extinction. The Kalash tribe has modernized its traditional Piranian clothing by adding embroidered ornaments and beads obtained from outside the Kalash Tribe environment. The existence of embroidery and bead ornaments on the traditional clothes of the Kalash Tribe is one of the elements that attracts the attention of people outside the Kalash Tribe so that they are able to attract tourists to visit their villages. The research method used is a qualitative experiment based on literature studies and observations of several references to the traditional dress of the world's tribes. Clothing and motifs in the Kalash Tribe culture inspired the design of women's ready-to-wear collections by applying A-Line and H-Line silhouettes. The textile design applied to the clothes is an element of gathering with the stylization of original motifs through embroidery and beading techniques. The results of the design of this women's readyto-wear collection are aimed at middle to upper class adult women with an age range of 23-33 years, sociable, cheerful, and feminine, have an attractive personality, love art and bright and bold colors.
\end{abstract}

Keywords: Beadings, Embroidery, Kalash Tribe, Modernization, Traditional Dress

Correspondence author: Dewi Isma Aryani,dewi.ia@art.maranatha.edu, Bandung, Indonesia 


\section{PENDAHULUAN}

Modernisasi adalah suatu proses transformasi dari suatu arah perubahan ke arah yang lebih maju atau meningkat dalam berbagai aspek kehidupan masyarakat. Tujuan utama dari modernisasi adalah untuk meningkatkan kualitas hidup masyarakat secara umum. Selain itu, modernisasi juga bertujuan untuk mengubah pola pikir seseorang menjadi lebih baik dalam berbagai bidang kehidupan sehingga dapat beradaptasi dengan kehidupan yang dinamis. Modernisasi juga dapat mencegah suku-suku di dunia agar tidak punah. Salah satu suku yang menerima modernisasi masuk ke dalam budaya masyarakatnya adalah Suku Kalash di Pakistan (Loude, 2017).

Suku Kalash menerima modernisasi masuk ke dalam budaya mereka melalui teknologi. Suku Kalash menerapkan modernisasi pada pakaian tradisional mereka yang bernama Piran, dengan menambahkan ornamen bordir menggunakan teknologi mesin. Masyarakat Kalash menggunakan bordir dan beadings warna-warni pada pakaian mereka. Motif bordir yang diterapkan merupakan gambaran lingkungan alam sekitar dan keseharian masyarakat Kalash itu sendiri. Masyarakat Suku Kalash juga menggunakan manik-manik dan kalung berwarna-warni sehingga menjadi hal pembeda dari suku lain di Chitral. Manik-manik yang didapat Suku Kalash dengan cara membeli dari pedagang di lingkungan luar Kalash. Manik-manik yang digunakan adalah manik plastik yang dibuat oleh pabrik (Mela, 2012).

Cara Suku Kalash menambahkan bordir dan beadings pada busana tradisional mereka adalah untuk mempercantik diri dan menarik minat pengunjung dari luar atau wisatawan, sehingga dapat membantu Suku Kalash bertahan menghadapi kepunahan. Banyaknya wisatawan yang datang ke perkampungan Suku Kalash akan dapat membantu perekonomian serta pemberitaan mengenai keunikan dan indahnya kebudayaan yang dimiliki Suku Kalash. Hal tersebut dibuktikan dari banyaknya buku dan dokumentasi film yang menceritakan kebudayaan dan keseharian Suku Kalash di Pakistan. Unsur beadings dan penerapan warna-warna cerah juga ditemukan di beberapa budaya suku-suku tradisional dunia, salah satunya adalah Suku Zulu seperti yang dipaparkan oleh Erliawati, et all (2018) dalam penelitian serupa berjudul "Perancangan Koleksi Busana Siap Pakai Deluxe Untuk Wanita dengan Inspirasi Simbol dan Warna Suku Zulu di Afrika”. Penelitian tersebut membuktikan bahwa warna merupakan bahasa yang universal karena memiliki dan mampu menyampaikan makna tertentu, sejalan pula dengan penelitian Fidelia dan Pratama (2018).

Suku Kalash sebagai suku minoritas yang berada di Chitral, Pakistan seringkali disebut kafir hingga terancam oleh kaum Muslim di Pakistan. Hal tersebut berakibat pada banyaknya masyarakat Suku Kalash yang memutuskan untuk berpindah kepercayaan. Masyarakat Kalash yang pindah kepercayaan menjadi Muslim dianggap keluar sebagai anggota Suku Kalash. Saat ini populasi Suku Kalash berjumlah sekitar 4.000 jiwa. Sebagai kelompok minoritas terbesar di Pakistan, Suku Kalash kaya dengan warna dan kehangatan dan hal tersebut sangat kontras dengan lingkungan di sekeliling perkampungan mereka yang cenderung tidak ramah (Ugurlu, 2020).

Keunikan budaya Suku Kalash yang tercermina dalam pakaian dan motifnya menjadi inspirasi dalam pembuat koleksi busana siap pakai wanita berjudul VENUS OF CHITRAL. Makna dari judul koleksi tersebut adalah keindahan dari wilayah Chitral, tempat Suku Kalash bermukim.

\section{METODE PENELITIAN}

Metode penelitian yang dilakukan adalah eksperimen kualitatif yakni studi literatur dan observasi beberapa referensi busana tradisional. Tahap studi literatur dan observasi tersebut merupakan tahap pra-produksi yakni pemilihan konsep busana dan meriset data yang ada dari artikel jurnal penelitian dan e-book. Selanjutnya setelah tahap riset selesai dilakukan, maka masuk ke tahap perancangan atau produksi busana.

Data kualitatif yang diperoleh dari studi literatur mengacu pada rumusan tren warna dan mode Indonesia Trend Forecasting for Indonesia Fashion Week 2020 "Fashion Re-formation" yakni tema Women Empowerment dan subtema Culture Festive. Analisis data dilakukan 
menggunakan metode $5 \mathrm{~W}+1 \mathrm{H}$ : What, Who, When, Where, Why, dan How. Tujuan analisis dengan metode $5 \mathrm{~W}+1 \mathrm{H}$ tersebut diharapkan dapat merumuskan hasil desain koleksi sesuai dengan data yang diperoleh.

1. What?

Terkait dengan permasalahan yang diangkat dalam perancangan ini adalah tentang keunikan motif dan warna pada pakaian tradisional Suku Kalash, Piran, yang berhiaskan kerajinan beadswork dan bordir untuk diterapkan ke dalam busana modern dengan tetap mempertahankan makna dari motif dan warna yang digunakan. Inspirasi tersebut kemudian digabungkan dengan tren dari Indonesia Trend Forecasting for Indonesia Fashion Week 2020 "Fashion Re-formation" dengan tema Women Empowerment dan subtema Culture Festive. Tren Women Empowerment mengangkat tema tentang femininitas, kuat, dan ceria pada seorang wanita, dan konsep ini sesuai dengan koleksi VENUS OF CHITRAL.

Subtema Culture Festive menunjukkan pattern-blocking dengan penerapan warna berani dan cerah, motif multibudaya eksentrik nan eksotis, serta memberikan kesan feminin serta ceria.

2. Who?

Berkaitan dengan sasaran dari perancangan yakni ditujukan untuk wanita urban berusia 2333 tahun bertempat tinggal di kota metropolitan seperti: Jakarta, Bandung, dan Surabaya, berkarakter yang feminin, ceria, mudah bergaul, menyukai warna-warna terang dan berani. Berprofesi di bidang seni seperti beauty blogger, menyukai dan menghargai seni.

3. Where?

Berkaitan dengan hasil perancangan ini ditempatkan agar dapat dijangkau oleh target market yang dimaksud. Sebagaimana telah disebutkan pada poin di atas bahwa hasil perancangan ini ditujukan bagi wanita urban berusia 23-33 tahun bertempat tinggal di kota metropolitan seperti Jakarta, Bandung, dan Surabaya. Pemilihan kota tersebut berdasarkan pada PP No. 26 Tahun 2008 tentang klasifikasi kategori kota berdasarkan jumlah penduduk yang dibagi menjadi empat, yakni kota kecil, sedang, besar, dan metropolitan. Salah satu ciri dari kota metropolitan adalah memiliki jumlah penduduk lebih dari 1.000.000 jiwa, dan hal tersebut sesuai dengan kondisi Kota Jakarta, Bandung, dan Surabaya. Hal tersebut juga diperkuat dengan adanya pergelaran acara-acara kesenian dan kebudayaan secara rutin.

4. When?

Berkaitan dengan waktu yang tepat untuk pemasaran produk yang dirancang. Berdasarkan data kualitatif yang diperoleh dari studi literatur maupun hasil observasi di lapangan (gerai window display produsen busana terkemuka, situs-situs online fashion dunia, serta terkait tren warna dan mode dalam Indonesia Trend Forecasting For Indonesia Fashion Week 2020 "Fashion Re-formation") maka waktu yang sesuai dengan produk yang dirancang ini adalah untuk Fall/ Winter 2020/2021.

5. Why?

Berkaitan dengan alasan mengapa produk ini perlu untuk dirancang yakni latar belakang ketertarikan penulis dengan kebudayaan suku minoritas di Pakistan, yaitu Suku Kalash yang memiliki kekayaan budaya akibat masuknya modernisasi dalam tradisi mereka. Keunikan tersebut berupa penerapan manik-manik dalam pakaian tradisional mereka, Piran, yang semula berwarna hitam menjadi lebih berwarna.

6. How?

Berkaitan dengan bagaimana membuat perancangan yang menarik dan sesuai dengan data yang diperoleh.

Berdasarkan latar belakang yang telah dipaparkan sebelumnya, maka rumusan dalam perancangan ini adalah: Bagaimana mengaplikasikan motif dan warna yang digunakan Suku Kalash ke dalam desain busana siap pakai untuk wanita menjadi busana yang menampilkan karakter feminin, etnik, bermotif detail dan modern? 


\section{HASIL DAN PEMBAHASAN}

Koleksi VENUS OF CHITRAL yang terinspirasi dari budaya Suku Kalash ini ditujukan untuk wanita dewasa dengan karakter yang feminin, ceria, dan mudah bergaul. Fabric manipulation yang diterapkan pada koleksi busana berupa bordir dan beadings, sesuai dengan ciri khas dan keahlian mayoritas Suku Kalash itu sendiri. Siluet yang diterapkan pada koleksi busana VENUS OF CHITRAL adalah A-Line dan H-Line. Adapun warna yang digunakan merupakan warna dari busana Piran yang didominasi warna hitam, sedangkan warna pink tua, biru muda, dan putih sebagai warna pelengkap yang diambil dari motif pada pakaian Suku Kalash.

\section{Makna Warna}

Koleksi busana siap pakai VENUS OF CHITRAL terinspirasi dari budaya Suku Kalash, terutama pakaian dan motifnya, menerapkan warna hitam, biru muda, pink tua, dan putih sebagai warna utama. Untuk warna sub-dominan yang digunakan adalah kuning dan hijau muda. Warna-warna yang digunakan diambil dari warna-warna pakaian dan motif Suku Kalash. Warna hitam merupakan warna dasar dari Piran sebagai pakaian tradisional Suku Kalash. Warna hitam digunakan Suku Kalash untuk menghormati pimpinan mereka terdahulu yaitu "Black Prince".

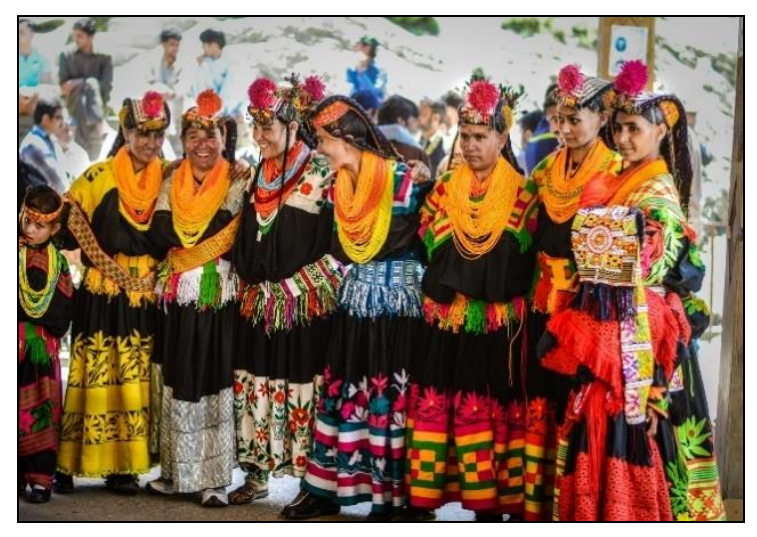

Gambar 1 Pakaian tradisional Suku Kalash saat ini

Warna pink yang banyak digunakan pada motif pada busana Piran memperlihatkan keceriaan dari Suku Kalash. Warna pink juga melambangkan feminitas dan warna lemah lembut dalam karakter seorang wanita, dan hal ini sesuai dengan koleksi busana VENUS OF CHITRAL yang memang ditujukan untuk wanita berkepibadian feminin. Warna biru muda dan putih juga banyak digunakan pada motif yang mencerminkan keadaan lingkungan sekitar Suku Kalash yang tinggal di perkampungan terpencil dikelilingi pegunungan dan sungai. Warna biru juga melambangkan kepercayaan, kesetiaan, dan kebijaksanaan. Oleh karena itu, warna biru digunakan dalam koleksi ini karena kesetiaan Suku Kalash pada budaya dan kepercayaannya yang kuat.

Berdasarkan ringkasan landasan teori warna tersebut, maka dapat ditampilkan ke dalam moodboard sebagai berikut: 


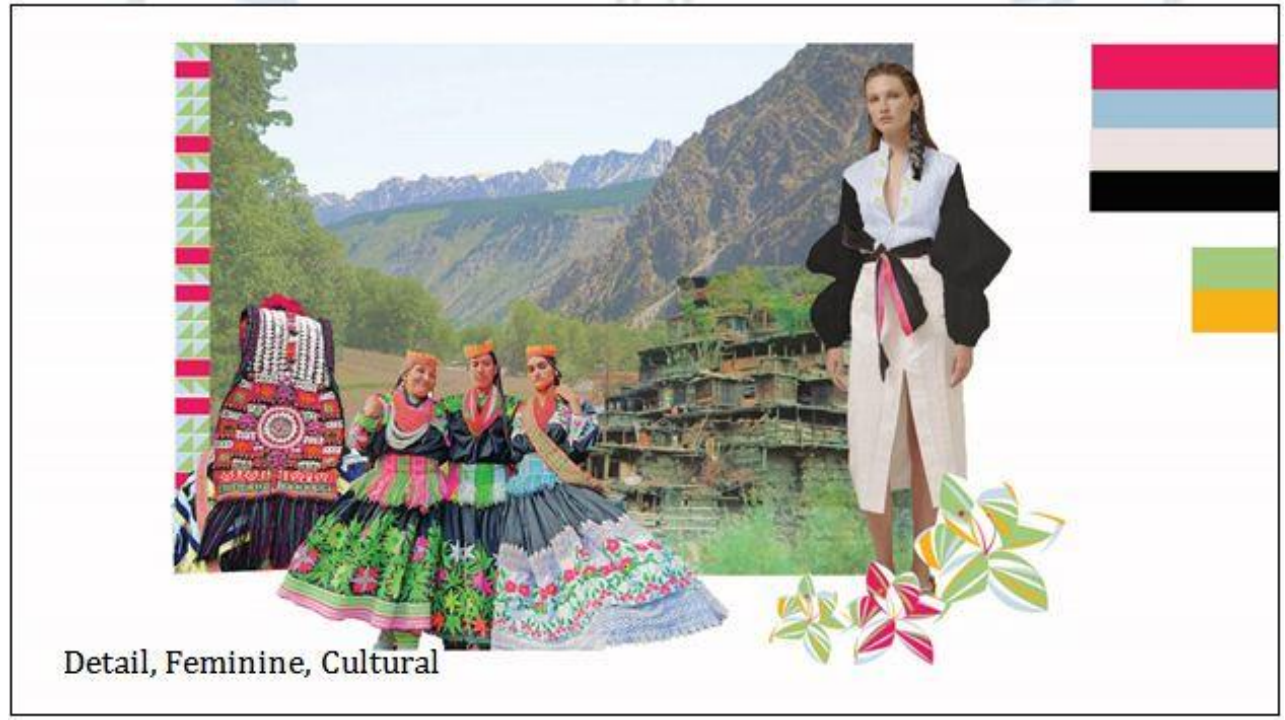

Gambar 2 Moodboard koleksi VENUS OF CHITRAL

\section{Teknik Reka Bahan}

Teknik manipulating fabric atau reka bahan merupakan teknik menyusun, mengatur, atau mengarang bahan yang dalam penelitian ini digunakan beberapa teknik sekaligus, antara lain:

1. Bordir

Bordir yang diterapkan dalam busana berfungsi sebagai hiasan di atas kain atau bahan-bahan lain menggunakan jarum jahit dan benang, biasanya membentuk pola-pola hiasan seperti: bunga, bentuk abstrak, binatang, dan lain-lain. Pembuatan bordir pada kain bertujuan untuk menciptakan keindahan pada baju atau pakaian sehingga akan tampak lebih menarik. Adapun motif bordir yang diaplikasikan pada koleksi VENUS OF CHITRAL berupa stilasi bunga dan bentuk kotak-kotak yang bertumpuk. Alasan pemilihan motif kotak-kotak bertumpuk dan bunga untuk koleksi VENUS OF CHITRAL karena kedua jenis motif tersebut sering digunakan sebagai motif pada Piran. Motif kotak bertumpuk merupakan repesentasi dari rumah tradisional masyarakat Suku Kalash atau dengan kata lain merupakan wujud stilasi dari tempat tinggal Suku Kalash di perkampungan Chitral yang tersusun rapi berbentuk kotak-kotak seperti rumah susun. Sedangkan motif bunga yang digunakan adalah bunga khas perkampungan Chitral yaitu Bunga Zerballi.

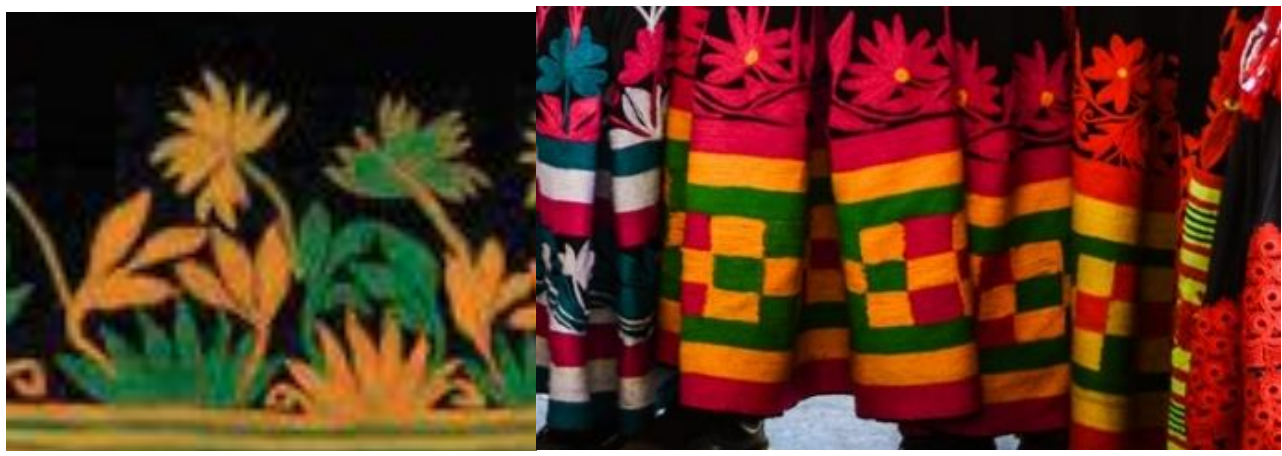

Gambar 3 Motif bunga dan kotak bertumpuk pada busana Piran 


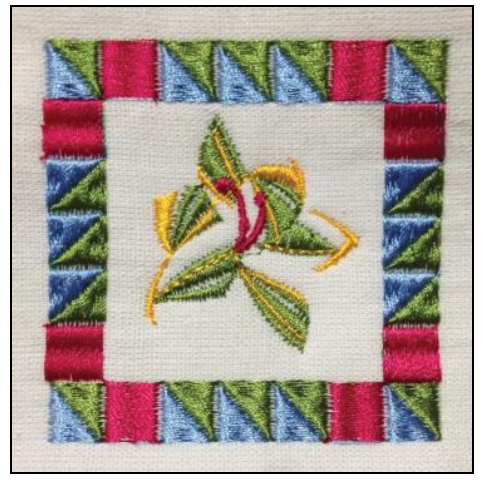

Gambar 4 Eksperimen bordir

\section{Beadings}

Beadings adalah salah satu teknik aplikasi imbuh/tambahan dengan beads/manikmanik menjadi material utama dalam penerapannya. Dalam Bahasa Indonesia, beadings dapat diartikan sebagai seni merangkai manik-manik. Adapun jenis manik-manik yang digunakan bisa berupa batu, kaca, plastik, kayu, mutiara air tawar, mutiara gelas, payet pasir, Kristal hingga batu-batuan berharga. Intinya teknik beadings dapat dilakukan selama ada lubang yang ditembus oleh material tersebut.

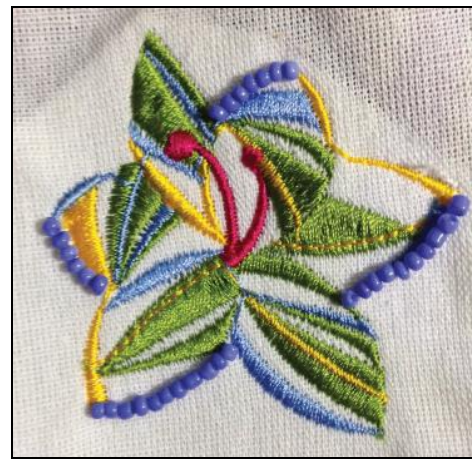

Gambar 5 Eksperimen beadings

Koleksi busana VENUS OF CHITRAL terdiri atas empat busana siap pakai yang pada setiap look terdapat manipulasi material berupa bordir dan beadings. Siluet yang diambil untuk koleksi busana VENUS OF CHITRAL juga terinspirasi dari busana tradisional Suku Kalash. Berikut adalah keempat desain busana pada koleksi VENUS OF CHITRAL:

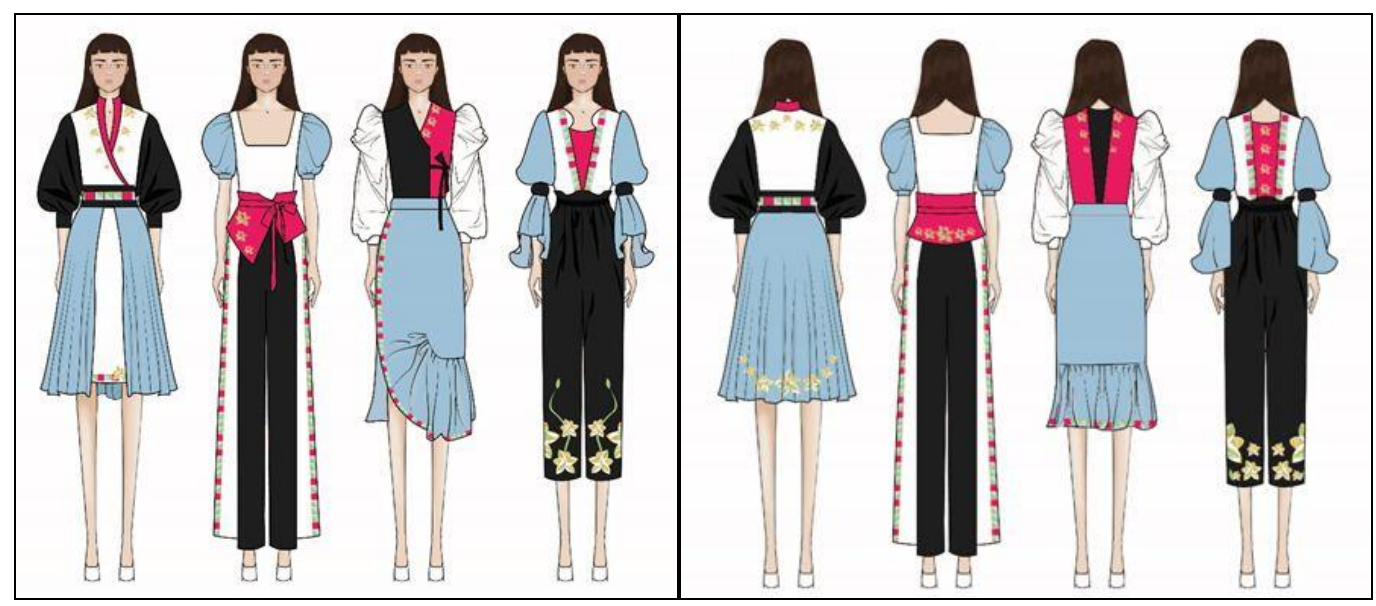

Gambar 6 Tampak depan dan belakang koleksi busana 
Pada koleksi busana VENUS OF CHITRAL, Penulis menggunakan acuan tren fashion yang dirumuskan oleh Indonesia Trend Forecasting for Indonesia Fashion Week 2020 berjudul Fashion Re-formation. Koleksi ini mengacu pada tren Women Empowerment dengan subtema Culture Festive. Tren Women Empowerment dipilih karena tren ini mengangkat tema dari sifat feminin, kuat, dan ceria sesuai dengan konsep yang diangkat ke dalam koleksi. Masyarakat Suku Kalash, khususnya wanita, merupakan pribadi-pribadi yang kuat dan tangguh karena berhasil membuat perubahan positif pada peradaban dan budaya sukunya. Wanita Suku Kalash juga bekerja mencari nafkah untuk membantu kaum pria Suku Kalash yang berjuang di kota. Dengan demikian, dapat diambil kesimpulan bahwa keseharian para wanita Suku Kalash memiliki peran ganda yakni sebagai pengurus sekaligus penopang dalam rumah tangga. Subtema Culture Festive menunjukkan pattern-blocking dengan penerapan warna berani dan cerah, motif multibudaya eksentrik nan eksotis, serta memberikan kesan feminin serta ceria. Sama seperti halnya Suku Kalash yang memiliki warna eksentrik dan keceriaan dalam kebudayaan mereka yang tak terbatas.

\section{Desain Busana 1}

Desain pertama dari koleksi VENUS OF CHITRAL merupakan dress dengan siluet $\mathrm{H}$ Line berlengan jenis bishop dipadukan dengan outer skirt satu lingkaran. Dress menggunakan material baby canvas dan katun Jepang pada bagian kerah. Sedangkan rok satu lingkaran menggunakan material katun toyobo. Detail busana diperlihatkan dengan adanya bordir stilasi bbentuk Bunga Zerballi di sekeliling opening atasan bagian depan serta di bagian back line. Outer skirt dilengkapi dengan obi belt yang diberikan bordir motif kotak bertumpuk. Pada bagian belakang outer skirt, terdapat bordiran motif Bunga Zerballi yang disusun organik melengkung ke atas untuk memberikan kesan yang lebih dinamis.

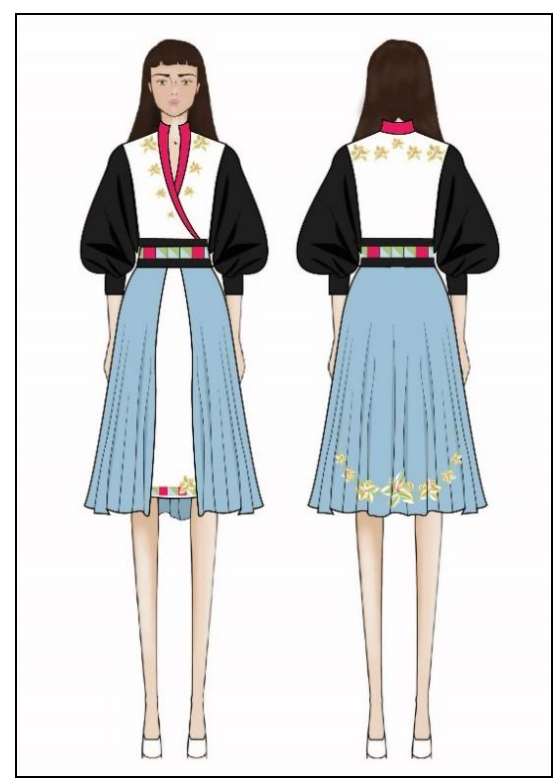

Gambar 7 Tampak depan dan belakang busana 1

\section{Desain Busana 2}

Desain kedua dari koleksi ini merupakan blouse dengan square neck dan lengan puff yang dipadukan dengan celana panjang asimetris ditambah aksen obi belt. Atasan dibuat dengan memadukan material baby canvas dengan toyobo. Obi berwarna pink dibuat dengan material katun jepang. Sedangkan celana dengan panjang asimetris dibuat menggunakan material baby canvas. Obi belt didesain asimetris dan berwarna pink terang sebagai focal point dari busana kedua ini dengan penambahan bordir Bunga Zerballi. Celana didesain asimetris dengan warna 
hitam dan putih untuk memberikan siluet ramping sekaligus unik karena di bagian samping garis celana terdapat aksen bordir motif kotak bertumpuk warna-warni.

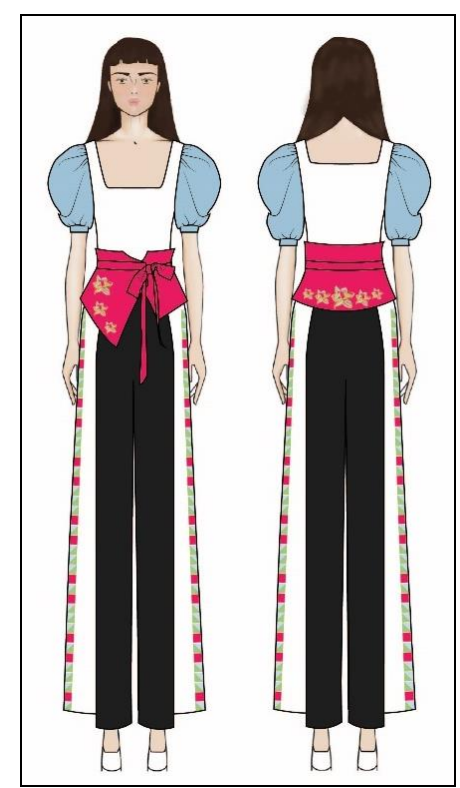

Gambar 8 Tampak depan dan belakang busana 2

\section{Desain Busana 3}

Desain ketiga dari koleksi VENUS OF CHITRAL ini berupa blouse dengan lengan leg of mutton. Blouse dipadukan dengan rok ruffle yang asimetris di bagian depan. Blouse menggunakan kain baby canvas dan katun jepang, sedangkan material rok menggunakan kain katun toyobo. Blouse dengan siluet seperti kimono memiliki dua warna berbeda di bagian depan dengan opening berupa tali yang dapat diikat di bagian samping. Aksen bordir Bunga Zerballi ditempatkan di atas material kain berwarna pink terang sebagai pemanis busana dan menambah kesan feminin. Sedangkan pada rok ditambahkan bordir dengan motif kotak bertumpuk yang lebih sederhana.

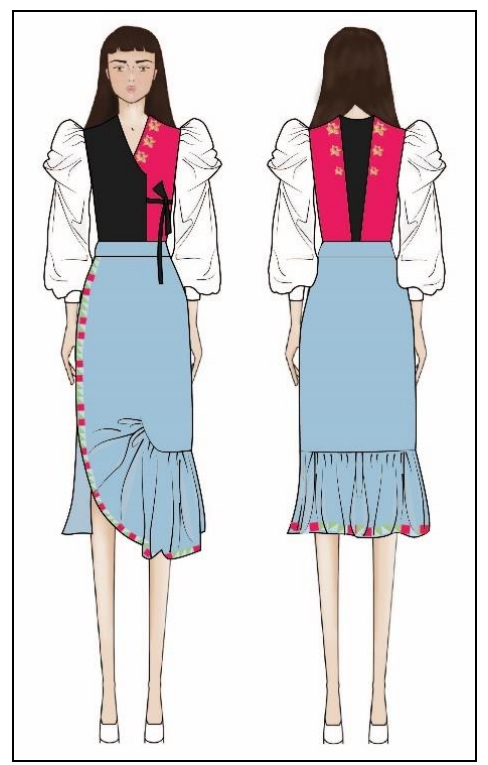

Gambar 9 Tampak depan dan belakang busana 3 


\section{Desain busana 4}

Desain keempat merupakan blouse dengan cutting yang unik dipadukan dengan celana paperbag. Blouse memadukan material baby canvas dengan katun jepang dan toyobo. Sedangkan celana paperbag menggunakan material baby canvas. Pada atasan busana keempat terdapat bordir kotak bertumpuk warna-warni dan di bagian punggung belakang terdapat bordir motif Bunga Zerballi yang disusun vertikal. Pada celana bagian bawah, Bunga Zerballi dibuat dengan tampilan motif yang lebih detail dibandingkan motif pada atasan sebagai unsur focal point dari busana keempat yang dominasi warnanya adalah hitam.

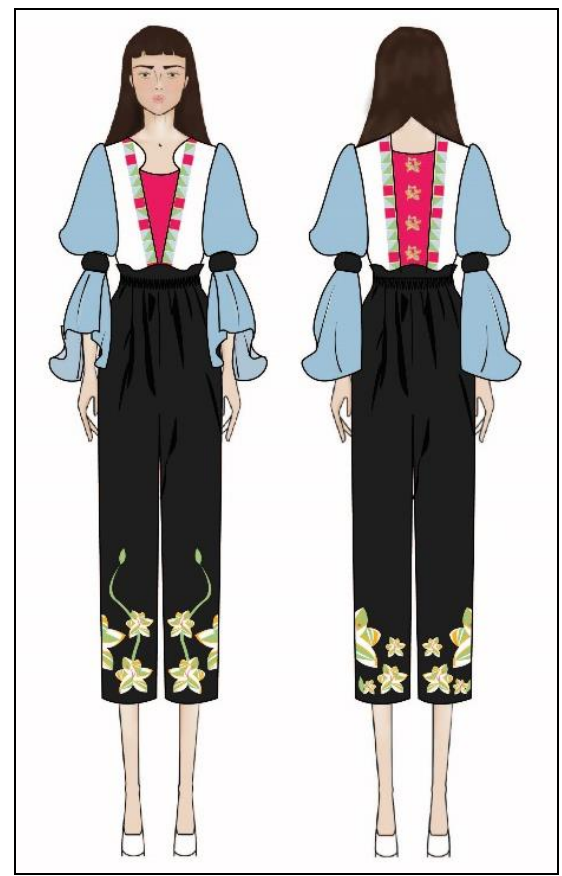

Gambar 10 Tampak depan dan belakang busana 4

Selain koleksi busana sebanyak empat tampilan, juga dilengkapi dengan dua buah desain alas kaki yang sesuai. Desain alas kaki pertama adalah sepatu jenis mules dengan tinggi hak empat sentimeter. Sedangkan desain alas kaki kedua adalah sepatu jeni stiletto hitam dengan hak setinggi lima sentimeter. Kedua desain sepatu tersebut semakin memberikan kesan feminin jika dikenakan bersama dengan koleksi busana VENUS OF CHITRAL. Material yang digunakan dalam pembuatan kedua desain sepatu adalah synthetic leather warna hitam dan putih. 


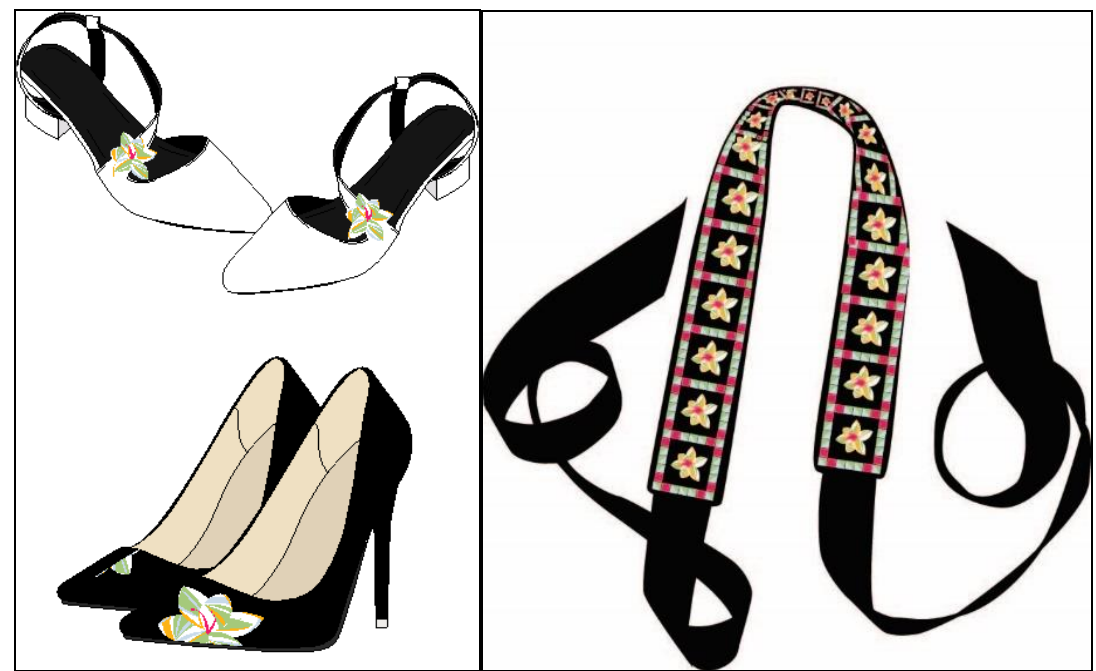

Gambar 11 Aksesori pelengkap koleksi VENUS OF CHITRAL

Selain alas kaki, terdapat aksesori pendukung yakni desain bando yang dibuat dari material canvas hitam dan pita. Pada desain bando dilengkapi manipulasi material berupa bordir motif Suku Kalash, seperti yang terdapat pada busana koleksi VENUS OF CHITRAL. Motif bordir Bunga Zerballi selain diterapkan pada busana juga diterapkan pada kedua sepatu sebagai unsur focal point. Sedangkan pada headpiece berupa bando motif bordir Bunga Zerballi dibuat lebih sederhana supaya dapat dipadu-padankan dengan motif kotak bertumpuk warna-warni.

\section{SIMPULAN}

Dampak dari adanya modernisasi terhadap suatu budaya biasanya memiliki akibat yang buruk. Namun, tidak demikian halnya pada Suku Kalash yang berhasil membuktikan bahwa modernisasi tidak selalu membawa dampak buruk bahkan sebaliknya. Dengan menerapkan modernisasi pada pakaian tradisional, Piran, Suku Kalash dapat menyelamatkan budaya mereka dari kepunahan. Suku Kalash menambahkan warna-warna cerah dari benang bordir dan manikmanik pada Piran sehingga mampu menarik perhatian masyarakat luar Chitral. Cara tersebut juga digunakan para wanita Suku Kalash untuk mempercantik diri mereka. Keputusan masyarakat Suku Kalash untuk membuat tampilan Piran menjadi lebih modern mampu membawa dampak yang baik bagi seluruh aspek kehidupan masyarakat Kalash.

Pakaian Piran khas Suku Kalash menjadi inspirasi dalam pembuatan koleksi busana siap pakai VENUS OF CHITRAL. Diharapkan dengan adanya koleksi busana VENUS OF CHITRAL ini dapat membantu mewujudkan sebuah busana siap pakai wanita melalui penerapan unsur-unsur tradisi dan budaya Suku Kalash. Koleksi busana VENUS OF CHITRAL merupakan koleksi busana siap pakai untuk wanita terinspirasi dari motif dan warna Suku Kalash yang terdapat pada pakaian tradisionalnya. Busana yang ditampilkan pada koleksi ini merepresentasikan gaya busana dengan detail pada busana berdasarkan pengaplikasian beads/ beadswork dan bordir.

\section{DAFTAR PUSTAKA}

Erliawati, T., Aryani, D. I., \& Tan, I. J. (2018). Perancangan koleksi busana siap pakai deluxe untuk wanita dengan inspirasi simbol dan warna suku Zulu di Afrika. ATRAT: Jurnal Seni Rupa, 6(3).

Fidelia, R., \& Pratama, D. (2018). Busana kerajaan tokoh Gatotkaca wayang kulit purwa gaya Surakarta. Visual Heritage: Jurnal Kreasi Seni dan Budaya, 1(01), 78-81.

Loude, J-Y., \& Liever, V. (2017). Kalasha solstice. Lyon: Ishi Press. 
Maggi, W. (2001). Our women are free. Umich edu. Diakses pada 2 Februari 2020 melalui https://www.press.umich.edu/pdf/0472097830-04.pdf.

Mela, E. (2012). The Kalasha woman today. International Journal of Humanities and Social Science, Vol. 2 No. 17, September 2012, h. 88-91.

Ugurlu, M. (2020). Kalash people in chitral. Diakses pada 2 Februari 2020 melalui https://www.aa.com.tr/en/pg/photo-gallery/kalash-people-in-pakistan.

https://www.ancient.eu/Kalasha/, diakses secara online pada 23 Februari 2020, pukul 10:29 WIB.

https://www.atlasobscura.com/places/kalasha-valleys-pagan, diakses secara online pada 19 Februari 2020, pukul 10:11 WIB. 